\title{
KAJIAN RESIKO GEMPA DENGAN PENDEKATAN METODE RAPID VISUAL SCREENING (RVS) FEMA 154 DAN 3D RESPONSE SPEKTRUM TERHADAP GEDUNG UNIVERSITAS WIJAYAKUSUMA PURWOKERTO
}

\author{
Novi Andhi Setyo Purwono'), Iwan Rustendi ${ }^{1)}$, Roesly Sakban'), dan \\ Ajeng Purba Kencana ${ }^{1)}$ \\ 1) Program Studi Teknik Sipil, Universitas Wijayakusuma Purwokerto \\ novi_andhisp@yahoo.com
}

\begin{abstract}
An earthquake is one that occurs as a result of a sudden shift in the soil layer below the earth's surface. Purwokerto as the city of Banyumas Regency is a city that is currently trying to develop as well as other big cities in Indonesia. The lecture building is a public service facility in terms of education for the community As the lecture building must be able to provide feasibility and comfort so that activities inside and outside the lecture building become comfortable. This aims of the reasearch to assess the vulnerability of several buildings at Wijayakusuma University to earthquakes. To find out the feasibility of the building, the analysis approach was carried out using the RVS method contained in FEMA 154, besides that the load calculation was carried out using SAP 2000 modeling with the 3D Response Spectrum method. The results showed that the multi-storey buildings at the University of Wijayakusuma Purwokerto were safe against earthquakes when assessed by the RVS method, whereas when assessed by the 3D response spectrum method in accordance with SNI 1726-2019 these buildings were less safe for fundamental natural vibration times, but for the third loading the building is safe.
\end{abstract}

Keywords: earthquake, RVS FEMA 154, 3D response spectrum 


\begin{abstract}
ABSTRAK
Gempa merupakan salah satu yang terjadi akibat kejadian pergeseran tiba-tiba dari lapisan tanah di bawah permukaan bumi. Purwokerto sebagai kota Kabupaten Banyumas adalah kota yang saat ini berusaha berkembang seperti halnya kota-kota besar lainnya yang ada di Indonesia. Gedung perkuliahan merupakan fasilitas pelayanan umum dalam hal pendidikan terhadap masyarakat Sebagai gedung perkuliahan harus mampu memberikan kelayakan dan kenyamanan sehingga aktivitas di dalam dan luar gedung perkuliahan menjadi nyaman. Penelitian ini bertujuan meninjau kerentanan beberapa bangunan yang terdapat pada Universitas Wijayakusuma terhadap gempa bumi. Untuk mengetahui kelayakan bangunan tersebut pendekatan analisa yang dilakukan dengan menggunakan metode RVS yang terdapat pada FEMA 154, selain itu perhitungan pembebanan dilakukan dengan pemodelan SAP 2000 dengan metode 3D Response Spektrum. Hasil penelitian menunjukkan bahwa gedung bertingkat pada Universitas Wijayakusuma Purwokerto aman terhadap gempa apabila dikaji dengan metode RVS, sedangkan apabila dikaji dengan metode $3 D$ response spectrum yang sesuai dengan SNI 1726-2019 gedung-gedung tersebut kurang aman untuk waktu getar alami fundamental, tetapi untuk pembebanan ketiga gedung tersebut aman.
\end{abstract}

Kata kunci: gempa bumi, RVS FEMA 154, 3D response spektrum 


\section{PENDAHULUAN}

Purwokerto sebagai kota Kabupaten Banyumas adalah kota yang saat ini berusaha berkembang seperti halnya kotakota besar lainnya yang ada di indonesia. Gedung perkuliahan merupakan fasilitas pelayanan umum dalam hal pendidikan terhadap masyarakat Sebagai gedung perkuliahan harus mampu memberikan kelayakan dan kenyamanan sehingga aktivitas di dalam dan luar gedung perkuliahan menjadi nyaman.

Menurut Howel dan Mulyo (2004) gempa bumi adalah suatu getaran ataupun serentetan getaran yang terjadi dari kulit bumi yang memiliki sifat sementara yang kemudian getaran tersebut menyebar ke segala arah. Ketika pergeseran ini terjadi, timbul getaran yang disebut gelombang seismik. Gelombang ini menjalar menjauhi fokus gempa ke segala arah di dalam bumi. Ketika gelombang mencapai permukaan bumi, getarannya bisa merusak atau tidak bangunan tergantung pada kekuatan gempa tersebut, disamping itu juga mutu bangunan dan mutu tanah dimana bangunan berdiri. Ketika terjadi gempa, struktur akan mengalami perpindahan secara vertikal dan horizontal. Gaya gempa arah vertikal jarang mengakibatkan keruntuhan struktur, namun gaya gempa arah horizontal akan menyebabkan keruntuhan karena gaya ini bekerja pada titik-titik lemah struktur.

Berdasarkan data BNPB, Indonesia merupakan daerah pertemuan dari 3 lempeng tektonik besar yaitu lempeng Indo-Australia, Eurasia, dan Pasific hal ini menjadikan Indonesia Sebagai Negara yang rawan terhadap gempa Bumi. Terbukti dengan adanya beberapa kejadian gempa di sejumlah wilayah Nusantara yang memakan cukup banyak korban, contohnya gempa Banten terjadi pada tanggal 2 Agustus 2019, gempa Donggala - Palu terjadi pada tanggal 28 September 2018, gempa Halmahera selatan terjadi pada tanggal 15 Juli 2019, sepanjang tahun 2019 tercatat sekitar 15 gempa bumi yang merusak terjadi di Indonesia. Dampak dari gempa bumi adanya korban jiwa, kehilangan harta benda, serta kerusakan infrastruktur baik retak-retak atau ambruk.

Menurut SNI 03-1726-2002 tentang standar perencanan ketahanan gempa untuk struktur bangunan. Bangunan yang harus memperhitungan beban gempa adalah bangunan yang memiliki tinggi lebih dari 4 lantai. Namun menurut FEMA (Federal Emergency Management Agency) 154 bangunan berlantai berapapun tetap layak diteliti, namun bangunan yang kurang dari 4 lantai akan lebih aman jika 
dibanding dengan bangunan yang memiliki 4 lantai atau lebih.

Dari beberapa Universitas yang ada di Purwokerto kami memilih Universitas Wijayakusuma Purwokerto sebagai objek untuk melakukan penelitian ini dengan berdasarkan beberapa pertimbangan seperti, data bangunan yang lengkap, umur bangunan yang sudah lebih 20 tahun sehingga perlu dilakukan peninjauan terhadap kekuatan bangunan.

Dalam penelitian ini, kami meninjau kerentanan beberapa bangunan yang terdapat pada UNWIKU (Universitas Wijayakusuma Purwokerto) terhadap gempa bumi. Supaya mengetahui apakah bangunan tersebut masih layak untuk digunakan atau tidak menggunakan RVS yang terdapat pada FEMA 154, selain itu kami juga menghitung pembebanan menggunakan pemodelan SAP2000 Mengetahui hal tersebut kami memilih ini untuk mengetahui kerentanan bangunan 3 lantai yang ada di Universitas Wijayakusuma Purwokerto terhadap gempa bumi dengan menggunakan metode rapid visual screening (RVS) FEMA 154 dan 3D (3 Dimensi) response spektrum. Universitas Wijayakusuma ini terletak di Jl. Raya Beji Karangsalam No. 25, Dusun III, Karangsalam Kidul, Kec. Kedungbanteng, Kabupaten Banyumas.

\section{KAJIAN PUSTAKA}

\subsection{Beban Mati}

Menurut SNI 03-1727-1989, beban mati adalah berat dari semua bagian dari gedung yang bersifat tetap, termasuk segala unsur tambahan,penyelesaian penyelesaian, mesin-mesin serta peralatan tetap yang merupakan bagian yang tak terpisahkan dari gedung tersebut.

\subsection{Beban Hidup}

Menurut SNI 03-1727-1989, beban hidup adalah semua beban yang terjadi akibat penghunian atau penggunaan suatu gedung dan termasuk benda-benda pada lantai yang berasal dari barang-barang yang dapat berpindah dan beban genangan maupun tekanan jatuh air hujan.

\subsection{Beban Gempa}

Menurut SNI, Beban gempa adalah semua beban yang bekerja pada suatu struktur akibat dari pergerakan tanah yang disebabkan karena adanya gempa bumi (baik itu gempa tektonik atau vulkanik) yang mempengaruhi struktur tersebut. Dalam perkembangannya, beban gempa dapat dihitung dengan cara statik ekivalen dan respon spektrum.

Respon spektrum menurut SNI 17262019. Spektrum respon adalah plot respons puncak atau kondisi mapan (perpindahan, kecepatan, atau percepatan) serangkaian 
osilator dengan frekuensi alami yang bervariasi yang dipaksa bergerak oleh getaran atau guncangan dasar yang sama. Berikut langkah-langkah menghitung beban gempa cara respon spektrum:

1. Penentuan beban gempa diperoleh data desain spektra dari website PUSKIM Indonesia dengan berdasarkan letak bangunan dan jenis tanah guna mendapatkan data tersebut.

2. Kemudian data tersebut diolah berdasarkan periode waktu getar.

3. Tentukan kategori resiko bangunan berdasarkan tabel 1 sesuai SNI 1726 - 2012.

4. Tentukan faktor keutamaan gempa berdasarkan kategori risiko gempa berdasarkan tabel 2 sesuai SNI 1726 - 2012.

Semua gedung dan struktur lain kecuali yang termasuk dalam kategori resiko I, III, IV termasuk, tapi tidak dibatasi untuk perumahan, toko atau pasar, gedung apartemen masuk kedalam kategori resiko II. Berdasarkan kategori resiko II maka faktor keutamaan gempa adalah 1.0 dan faktor $\mathrm{R}$ untuk system penahan gaya gempa $(\mathrm{R})$ sebesar 5.5.

\section{$2.4 \quad$ RVS FEMA 154}

Rapid Visual Screening (RVS) adalah metode identifikasi suatu bangunan secara cepat tanpa harus menganalisa bangunan dengan menggunakan software. Untuk mengidentifikasi tingkat risiko suatu bangunan terhadap ancaman gempa bumi, bisa dilakukan dengan RVS pada tahap permulaannya. Kemudian hasil dari RVS bisa menentukan apakah gedung yang di evaluasi tersebut berisiko atau tidak, kalau berersiko maka akan dilanjutkan ke evaluasi FEMA berikutnya.

\section{METODE PENELITIAN}

\subsection{Data Primer}

Menurut Narimawati (2008) dalam bukunya "Metodologi Penelitian Kualitatif dan Kuantitatif: Teori dan Aplikasi” bahwa: "Data primer ialah data yang berasal dari sumber asli atau pertama. Data ini tidak tersedia dalam bentuk terkompilasi ataupun dalam bentuk filefile. Dalam penelitian ini, data primer diperoleh dari kondisi dilapangan pada saat peninjauan. 


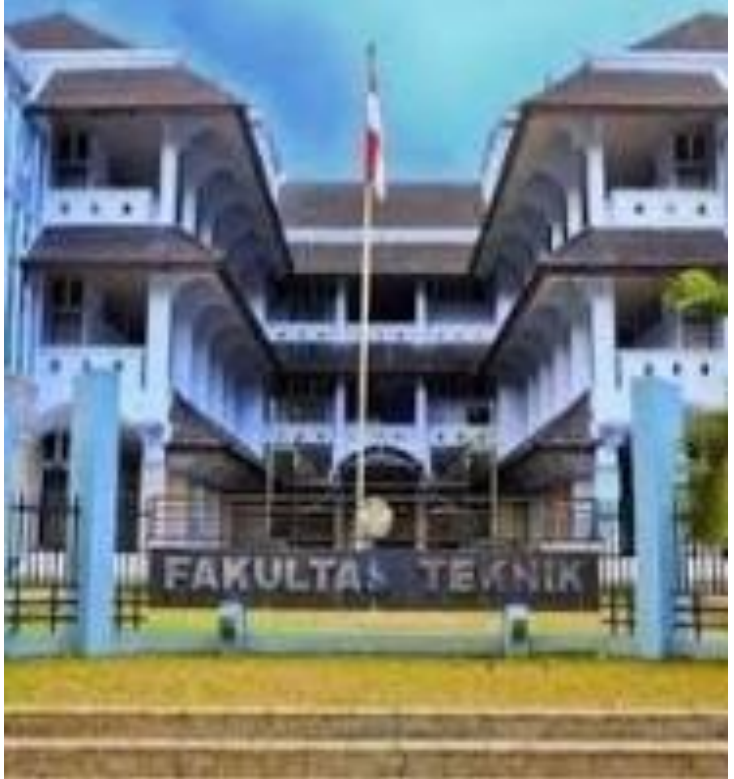

Gambar 1. Gedung Fakultas Teknik

\subsection{Data Sekunder}

Data sekunder adalah data yang mengacu pada

informasi yang dikumpulkan dari sumber yang telah ada. Sumber data sekunder adalah catatan atau dokumentasi perusahaan, publikasi pemerintah, analisis industri oleh media, situs Web, internet dan seterusnya (Sekaran, 2011). Sedangkan menurut (Sugiono, 2008) data sekunder adalah sumber data yang tidak langsung memberikan data kepada pengumpul data. Pada penelitian ini data sekunder yang dimaksud adalah sebagai berikut:

1. File database

File database ini kurang lebih berisi informasi tentang usia bangunan, luas lantai dan jumlah lantai yang bisa diperoleh dari sejarah bangunan tersebut.

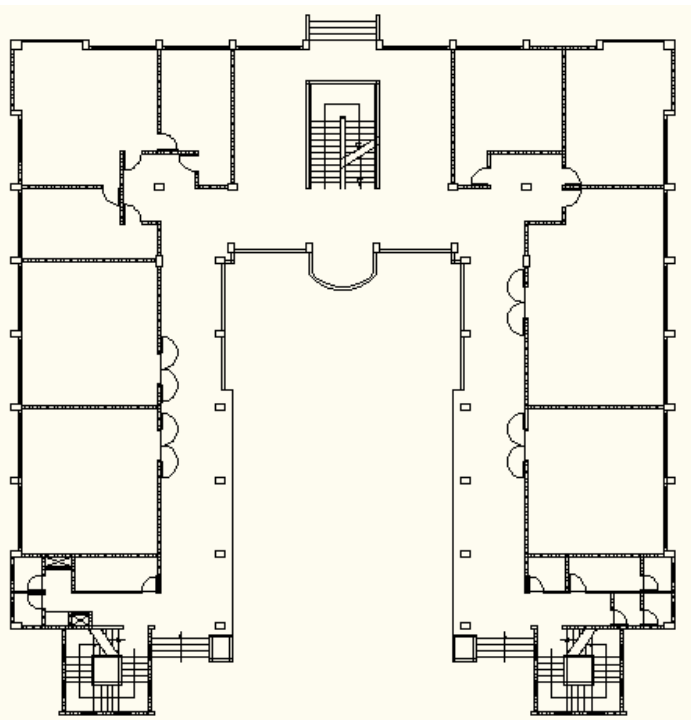

Gambar 2. Denah Fakultas Teknik

2. Gedung departemen file

Luas dan kelengkapan informasi dalam data bangunan akan bervariasi dari setiap wilayah. Sebagai contoh, di beberapa lokasi semua file lama telah dihapus atau hancur, sehingga tidak ada informasi tentang bangunan yang sudah tua. Secara umum, file (atau mikrofilm) dapat berisi izin, rencana dan perhitungan struktur yang diperlukan untuk arsip pemerintah kota. Kadang-kadang ada informasi hunian dan penggunaannya, tetapi sedikit informasi tentang jenis struktural. 


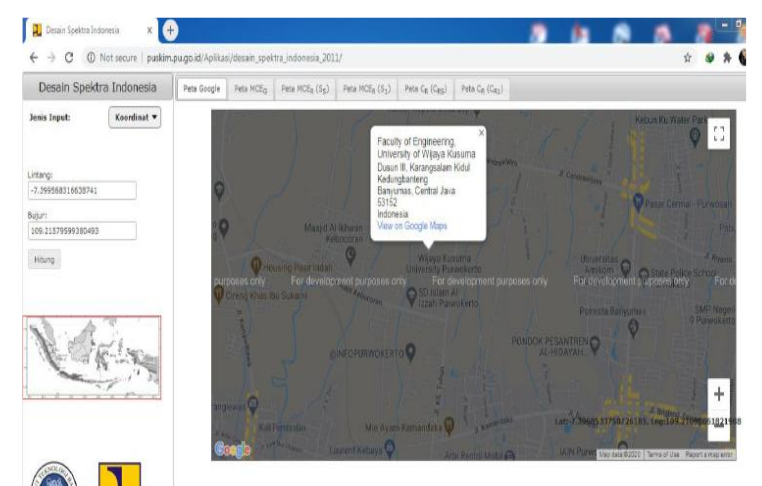

(0)

\section{Gambar 3. Data seismic wilayah Sumber: Puskim}

3. Database wilayah

Dengan meluasnya penggunaan internet, banyak pemerintah kota menciptakan database elektronik "online" untuk diakses oleh masyarakat umum. Database ini menyediakan informasi umum tentang berbagai situs. Database ini biasanya tidak cukup memberikan informasi spesifik tentang bangunan, namun sudah cukup memberikan beberapa informasi yang bisa berguna untuk RVS skrining.

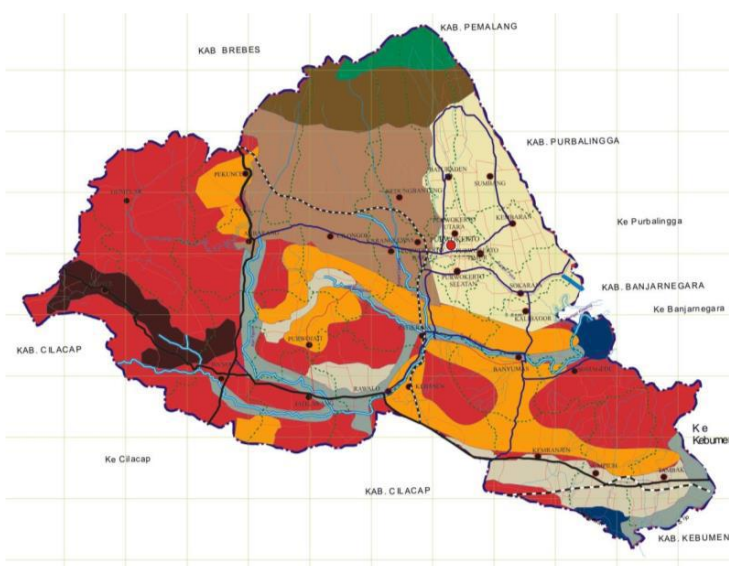

Gambar 4 Peta Jenis Tanah Banyumas Sumber: Google
4. Studi atau penelitian sebelumnya

Untuk referensi bisa dicari studi mengenai kerentanan gempa di alamat terkait seperti pencairan atau Potensi longsor.

\section{Informasi tanah}

Jenis tanah memiliki pengaruh besar pada amplitudo dan periode getaran, dan dengan demikian mempengaruhi kerusakan struktural. Karena kondisi tanah tidak dapat langsung diidentifikasi oleh metode visual di lapangan, maka harus dikumpulkan peta geologi dan geoteknik serta informasi lainnya. Semua itu bisa disiapkan selama tahap perencanaan dan dimasukkan catatan untuk digunakan selama RVS.

\section{HASIL DAN PEMBAHASAN}

\subsection{Pengisian RVS}

Universitas Wijayakusuma terletak di moderately high seismicity menurut FEMA, namun jika menurut SNI 17262019 berada pada moderate seismicity. Maka pada penelitian ini digunakan formulir RVS Moderately High Seismicity, namun juga tetap mencoba formulir RVS yang moderate seismicity yang akan digunakan sebagai pembandingnya (Tabel 1, Tabel 2, dan Tabel 3. 
Tabel 1. Pengisian Formulir RVS di Fakutas Teknik

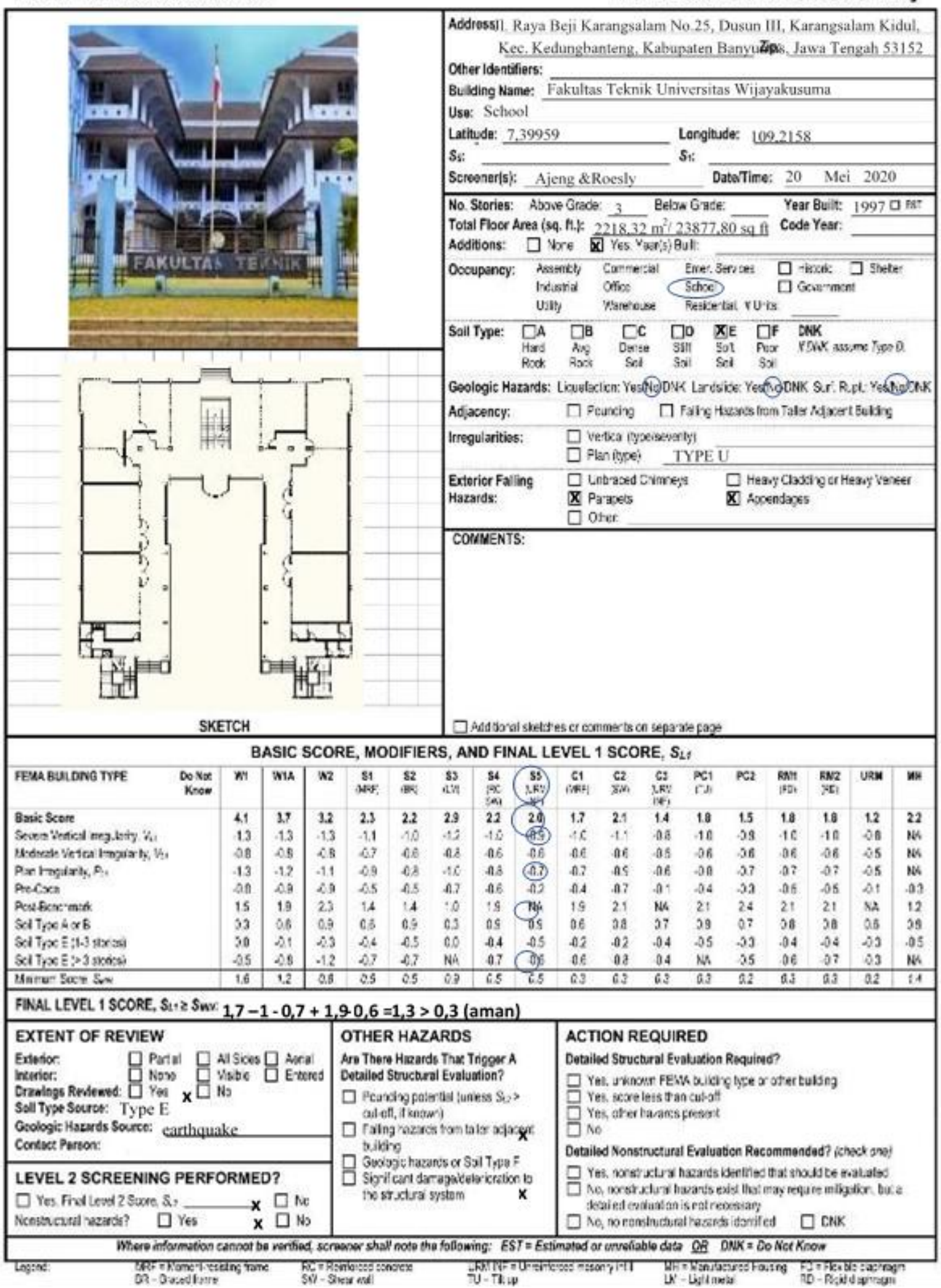


Tabel 2. Pengisian Formulir RVS di Fakutas Peternakan

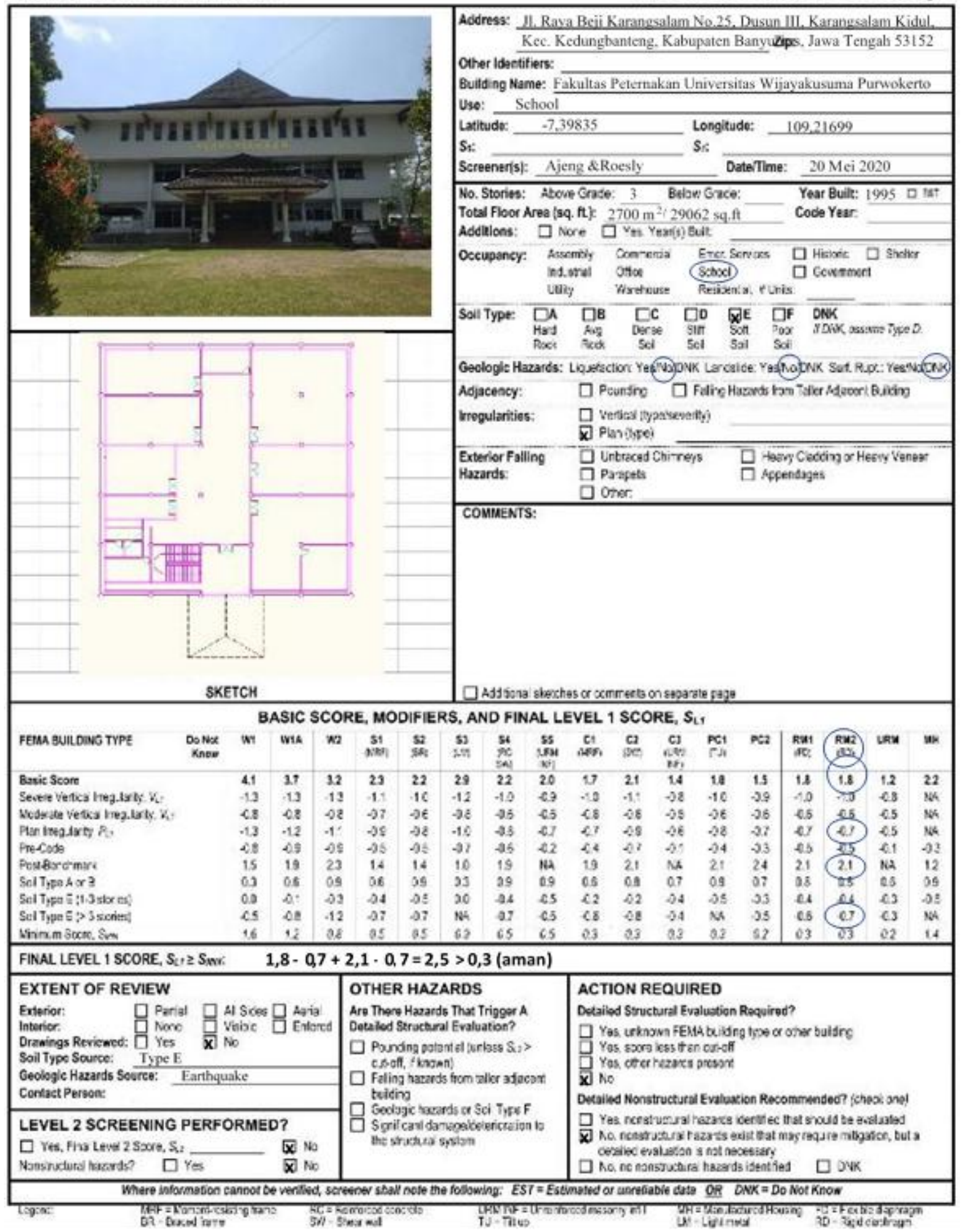


Tabel 3. Pengisian Formulir RVS di Fakutas Ekonomi dan Bisnis

Rapid Visual Screening of Buildings for Potential Seismic Hazards FEMA P-154 Data Collection Form

Level 1

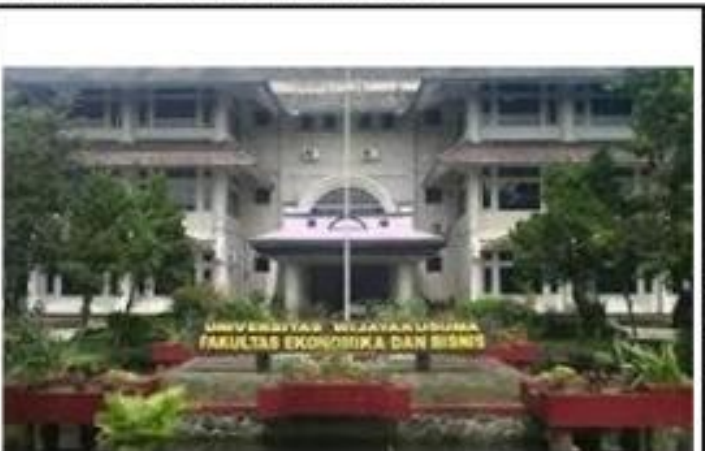

MODERATELY HIGH Seismicity

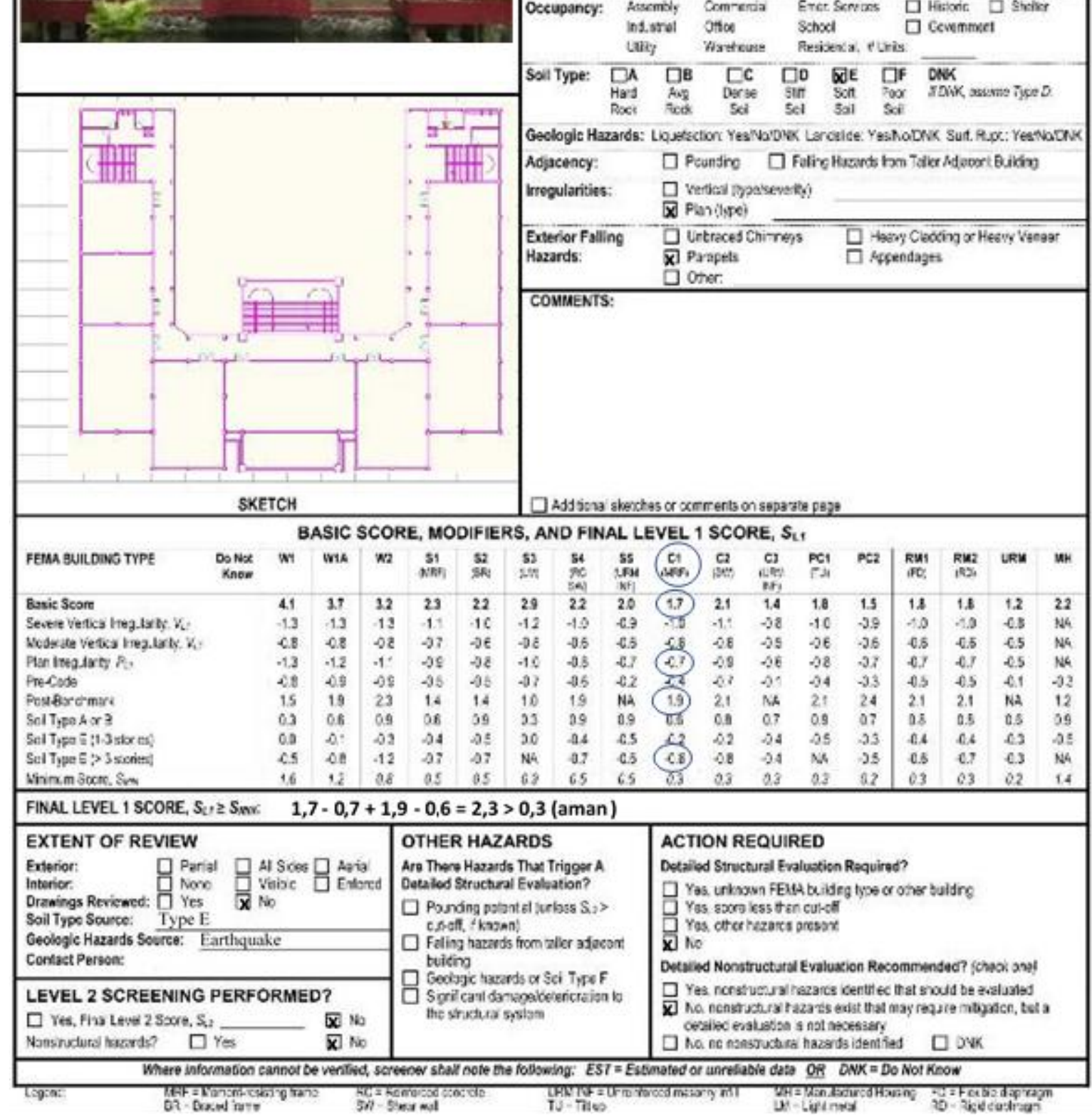




\subsection{Analisis Struktur}

Pembatasan simpangan antar lantai suatu struktur bertujuan untuk mencegah kerusakan non-struktur dan ketidaknyamanan penghuni. Berdasarkan SNI 1726-2019, Simpangan antar tingkat desain tidak boleh melebihi simpangan antar tingkat izin. Hasil simpangan antar lantai untuk masing-masing fakultas dapat dilihat pada Tabel 4, Tabel 5, dan Tabel 6 . Perbandingan

Tabel 4. Simpangan Antar Tingkat untuk Fakultas Teknik

\begin{tabular}{|c|c|c|c|c|c|c|c|}
\hline \multirow{2}{*}{ Lantai } & \multirow{2}{*}{$\begin{array}{l}\text { Tinggi } \\
\text { Tiap } \\
\text { Lantai } \\
(\mathrm{mm})\end{array}$} & \multicolumn{5}{|c|}{ Gempa Arah X } & \multirow{2}{*}{ Ket. } \\
\hline & & $\delta \mathrm{x}$ & $\delta y$ & $\Delta \mathrm{x}(\mathrm{mm})$ & $\Delta \mathrm{y}(\mathrm{mm})$ & $\Delta \mathrm{ijin}(\mathrm{mm})$ & \\
\hline Atap & 4000 & 19.5 & 19.5 & 10.3 & 10.6 & 100 & aman \\
\hline 3 & 4000 & 17.2 & 17.4 & 20.7 & 24.6 & 100 & aman \\
\hline 2 & 4000 & 12.6 & 12.6 & 29.5 & 36.2 & 100 & aman \\
\hline 1 & 4000 & 6.1 & 6.0 & 27.4 & 37.4 & 100 & aman \\
\hline 0 & 0 & 0 & 0 & 0 & 0 & 0 & aman \\
\hline
\end{tabular}

Tabel 5. Simpangan Antar Tingkat untuk Fakultas Teknik Ekonomi dan Bisnis

\begin{tabular}{|c|c|c|c|c|c|c|c|}
\hline \multirow{2}{*}{ Lantai } & \multirow{2}{*}{$\begin{array}{l}\text { Tinggi } \\
\text { Tiap } \\
\text { Lantai } \\
(\mathrm{mm})\end{array}$} & \multicolumn{5}{|c|}{ Gempa Arah X } & \multirow{2}{*}{ Ket. } \\
\hline & & $\delta \mathrm{x}$ & $\delta y$ & $\Delta \mathrm{x}(\mathrm{mm})$ & $\Delta \mathrm{y}(\mathrm{mm})$ & $\Delta \mathrm{ijin}(\mathrm{mm})$ & \\
\hline Atap & 4200 & 18.9 & 18.2 & 12.1 & 9.6 & 105 & aman \\
\hline 3 & 4200 & 14.2 & 14.4 & 18.5 & 24.6 & 105 & aman \\
\hline 2 & 4200 & 8.5 & 9.1 & 22.0 & 36.2 & 105 & aman \\
\hline 1 & 4200 & 2.9 & 3.4 & 14.4 & 37.4 & 105 & aman \\
\hline 0 & 0 & 0 & 0 & 0 & 0 & 0 & aman \\
\hline
\end{tabular}

Tabel 6. Simpangan Antar Tingkat untuk Fakultas Teknik Ekonomi dan Bisnis

\begin{tabular}{|c|c|c|c|c|c|c|c|}
\hline \multirow{2}{*}{ Lantai } & \multirow{2}{*}{$\begin{array}{l}\text { Tinggi } \\
\text { Tiap } \\
\text { Lantai } \\
(\mathrm{mm})\end{array}$} & \multicolumn{5}{|c|}{ Gempa Arah X } & \multirow{2}{*}{ Ket. } \\
\hline & & $\delta \mathrm{x}$ & $\delta y$ & $\Delta \mathrm{x}(\mathrm{mm})$ & $\Delta \mathrm{y}(\mathrm{mm})$ & $\Delta$ ijin $(\mathrm{mm})$ & \\
\hline Atap & 4000 & 20.5 & 20.0 & 16.7 & 16.4 & 100 & $\overline{\text { aman }}$ \\
\hline 3 & 4000 & 17.5 & 17.0 & 27.8 & 27.5 & 100 & aman \\
\hline 2 & 4000 & 12.3 & 12.0 & 37.1 & 36.9 & 100 & aman \\
\hline 1 & 4000 & 5.5 & 5.3 & 29.1 & 29.2 & 100 & aman \\
\hline 0 & 0 & 0 & 0 & 0 & 0 & 0 & aman \\
\hline
\end{tabular}

Tabel 7. Perbandingan FEMA 154 dan SNI 03-1726-2019

\begin{tabular}{cccc}
\hline \multirow{2}{*}{ Nama Gedung } & \multicolumn{2}{c}{ FEMA 154 } & \\
\cline { 2 - 3 } & $\begin{array}{c}\text { Moderately } \\
\text { High Seismicity }\end{array}$ & $\begin{array}{c}\text { Moderate } \\
\text { Seismicity }\end{array}$ & SNI 03-1726-2019 \\
\hline $\begin{array}{c}\text { Fakultas Teknik } \\
\begin{array}{c}\text { Fakultas Ekonomi } \\
\text { dan Bisnis }\end{array}\end{array}$ & Memenuhi & Memenuhi & $\begin{array}{c}\text { Tidak memenuhi waktu control fundamental alami } \\
\text { namun memenuhi waktu control drift (simpangan) }\end{array}$ \\
$\begin{array}{c}\text { Fakultas } \\
\text { Peternakan }\end{array}$ & Memenuhi & Memenuhi & $\begin{array}{l}\text { Tidak memenuhi waktu control fundamental alami } \\
\text { namun memenuhi waktu control drift (simpangan) } \\
\text { Tidak memenuhi waktu control fundamental alami } \\
\text { namun memenuhi waktu control drift (simpangan) }\end{array}$ \\
\hline
\end{tabular}




\section{SIMPULAN}

Penelitan ini bertujuan untuk mengetahui kekuatan bangunan yang diteliti terhadap gempa. Dalam pelaksanaannya penelitian ini penulis dapat menyimpulkan beberapa hal di antaranya:

1. Hasil dari penelitian ini adalah ketiga bangunan yang diteliti aman, jika menggunakan metode RVS.

2. Jika menggunakan metode 3D response spektrum yang sesuai dengan SNI 1726-2019 adalah bangunan tersebut kurang aman untuk waktu getar alami fundamental, namun untuk pembebanan ketiga bangunan tersebut masih aman.

\section{DAFTAR PUSTAKA}

Anonim. (1998). Handbook for the Seismic Evaluation of Buildings - A Prestandard, prepared by the American Society of Civil Engineers for the Federal Emergency Management Agency, FEMA 310 Report. Washington D.C: ASCE.

Anonim. (2008). Peraturan Menteri Pendidikan Nasional Nomor 33 Tahun 2008. Jakarta: Menteri Pendidikan Nasional.

Anonim. (2015a). Rapid Visual Screening of Buildings for Potential Seismic Hazards: A Handbook (Third edition), Federal Emergency Management Agency, FEMA P-154
Report. Washington D.C: ATC.

Anonim. (2015a). Rapid Visual Screening of Buildings for Potential Seismic Hazards: A Handbook (Third edition), Federal Emergency Management Agency, FEMA P-155 Report. Washington D.C: ATC.

Anonim. (2018a). Profil Kota/Kabupaten Banyumas. Banyumas: Direktorat Jenderal Cipta Karya.

Anonim. (2018b). Data dan Informasi Bencana Indonesia. Jakarta: Badan Nasional Penanggulangan Bencana.

Anonim. (2019). SNI 03-1726-2019 tentang Tata Cara Perencanaan Ketahanan Gempa untuk Struktur Bangunan Gedung dan Nongedung. Jakarta: Badan Standardisasi Nasional.

Achs, G., \& Adam, C. (2012). A RapidVisual-Screening Methodology for the Seismic Vulnerability Assessmenof Historic BrickMasonry Building in Vienna. Bull Earthquake Eng., 10, 1833-1856.

Hartanty, D. W. D. (2015), Analisis kerentanan suatu Bangunan terhadap resiko gempa menggunakan metode Rapid Visual Screening (RVS) FEMA 154 pada zona gempa sedang. Tugas Akhir: Institut Teknologi Sepuluh November.

Joshi, G. C., \& Kumar, R. (2010). Preliminary Seismic Vulnerability Assessment of Mussoorie Town, Uttarakhand (India). Journal of Building Appraisal, 5, 357-368.

Astuti, N. D., Sangadji. S., \& Rahmadi, A. P. (2016) Evaluasi Awal Resiko seismik bangunan gedung RUSUNAWA. Seminar Nasional Sains dan Teknologi. Jakarta: Fakultas Teknik Universitas Muhammadiyah Jakarta. 
Sobaih, M. E., \& Nazif, M. A. (2012). A Proposed Methodology for Seismic Risk Evaluation of Existing reinfrced School Building. HBRC Journal, 8, 204-211.

Sakban R., \& Kencana, A. P. (2020). Analisis kerentanan bangunan gedung bertingkat Universitas Wijayakusuma Purwokerto terhadap resiko gempa dengan metode rapid visual screening (RVS) FEMA 154 dan $3 D$ response spektrum. Tugas Akhir: Fakultas Teknik, Universitas Wijayakusuma Purwokerto 